Available online on 15.09.2020 at http://jddtonline.info
Open Access to Pharmaceutical and Medical Research
unrestricted non-commercial use, provided the original work is properly cited

Open $\odot$ Access

Research Article

\title{
Total Phenolic Contents and Antioxidant Properties of Algerian Alkanna tinctoria aerial part Extracts
}

\author{
Thoraya Guemmaz*, Lekhmici Arrar and Abderrahmane Baghiani \\ Laboratory of Applied Biochemistry, University of Setif 19000, Setif-1, Algeria
}

\begin{abstract}
Objective: Evaluation of the polyphenols, flavonoids and tannins contents of different aqueous extracts of the aerial part of Alkanna tinctoria and their antioxidant activities.

Methodology: Three extracts; decoction, macerate and infusion of the aerial part of Alkanna tinctoria were prepared. The content of total polyphenols, flavonoids and tannins of the extracts was carried out and antioxidant activity was assessed using DPPH (2,2'-diphenyl-1-picryl hydrazyl), $\beta$-carotene bleaching and iron chelation tests.

Results: The results showed that Infusion (Inf) was the richest in total polyphenols (189.66 $\pm 30.77 \mathrm{mg}$ EGA / g of dried extract) and flavonoids $(26.80 \pm 8.37 \mathrm{mg}$ EQ / g of dried extract). While the content of tannins is almost the same for Dec and Inf $(40.27 \pm 15.00,40.25 \pm$ $18.27 \mathrm{mg}$ ETA / g of dried extract). Moreover, the two extracts Inf (IC 50 of $0.09 \pm 0.0015 \mathrm{mg} / \mathrm{ml}$ ) and Dec (IC 50 of $0.17 \pm 0.031 \mathrm{mg} / \mathrm{ml}$ ) showed a very strong anti-radical activity towards the radical DPPH. In the $\beta$-carotene bleaching test, Inf and Dec showed a significant inhibitory activity of peroxidation with values of $100 \%$ and $99.8 \%$ and are more effective compared to BHT (98.15\%). Dec and Mac showed strong chelating activity with $\mathrm{IC}_{50} \mathrm{~S}$ of $0.003 \pm 0.0002 \mathrm{mg} / \mathrm{ml}$ and $0.005 \pm 0.00008 \mathrm{mg} / \mathrm{ml}$ respectively. These chelating activities remain higher than EDTA.
\end{abstract}

Conclusion: It may be concluded that the extracts of the aerial part of Alkanna tinctoria exhibit significant both content of polyphenols and antioxidant activity.

Keywords: Alkanna tinctoria, polyphenols, flavonoids, antioxidant activity.

Article Info: Received 07 August 2020; Review Completed 11 August 2020; Accepted 16 August 2020; Available online 15 September 2020

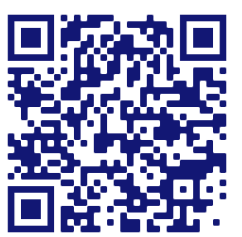

Cite this article as:

Guemmaz T, Arrar L, Baghiani A, Total Phenolic Contents and Antioxidant Properties of Algerian Alkanna tinctoria aerial part Extracts, Journal of Drug Delivery and Therapeutics. 2020; 10(5):39-44

http://dx.doi.org/10.22270/jddt.v10i5.4349

Thoraya Guemmaz, Laboratory of Applied Biochemistry, University of Setif 19000, Setif-1, Algeria

\section{INTRODUCTION}

Medicinal plants have a wide variety of biological and pharmacological activities. They are reservoirs for a wide variety of secondary metabolites, including alkaloids, flavonoids, tannins and terpenoids 1 . These compounds are secondary metabolites involved in different functions in plants. They have various biological activities, in particular the antioxidant potential, in particular against the oxidative process induced by reactive oxygen species which are the direct cause of various pathological states such as aging and cancer ${ }^{2}$.

Among these plants, Alkanna tinctoria (AT) known as Orchanet, in Arabic Aoud Hawaa ${ }^{3}$. Alkanna is a genus of herbaceous plants including about 50 species of the family Boraginacea, originally from Europe, the Mediterranean and Western Asia ${ }^{4}$. Alkanna tinctoria found in Europe, W. Asia, and N. Africa, and known to the Greeks (described by Theophrastus and the Romans), has been used since antiquity ${ }^{5}$. This plant is widely used against jaundice, and kidney stones, it has an antibacterial, astringent and vulnerary effect. It is used in the treatment of ulcers, inflammation and burns 6,7. To our knowledge, research on aqueous extracts from the aerial part of Alkanna tinctoria is very limited. This work was undertaken to evaluate the antioxidant activities of extracts from the aerial part of Alkanna tinctoria, a plant whose use is very limited in traditional medicine in Algeria.

\section{MATERIAL AND METHODS}

\section{Plant material}

The plant (Alkanna tinctoria) AT was harvested at the end of June 2017, in the region of Setif, Algeria. It was identified by Pr. Oudjhih Bachir, Elhadj Lakhdar University, Batna. The aerial part of this plant was washed and cut, then dried in the shade and at room temperature, then crushed and stored until use. 


\section{Preparation of extracts}

\section{Decoction}

A weighing of $20 \mathrm{~g}$ of fine powder of the plant is added to $200 \mathrm{ml}$ of boiling distilled water. The mixture was kept boiling with stirring for $20 \mathrm{~min}$. The decoction (Dec) is then centrifuged and then filtered through filter paper and dried in an oven at $40^{\circ} \mathrm{C}$ until total evaporation of water ${ }^{8}$.

\section{Maceration}

A macerate of the plant is obtained by adding $20 \mathrm{~g}$ of fine powder to $200 \mathrm{ml}$ of distilled water. The mixture was stirred for 24 hours at room temperature. The macerate (Mac) is then centrifuged and then filtered through filter paper and dried in an oven at $40^{\circ} \mathrm{C}$ until complete evaporation of water ${ }^{9}$.

\section{Infusion}

A weighing of $20 \mathrm{~g}$ of fine powder of the plant is added to $200 \mathrm{ml}$ of boiling distilled water. The mixture is stirred for $15 \mathrm{~min}$ at room temperature. The infusion (Inf) is then centrifuged and then filtered through filter paper and dried in an oven at $40^{\circ} \mathrm{C}$ until complete evaporation of water 10 .

\section{Quantitative estimation of polyphenols, flavonoids and} tannins

\section{Estimation of total phenolic content}

The total phenol content of the aqueous extracts was determined according to the Folin-Ciocalteu method 11. Different concentrations of each extract were mixed with $500 \mu \mathrm{l}$ of Folin Ciocalteu reagent (diluted 10 times) and incubated at room temperature for 4 minutes. Then $400 \mu \mathrm{l}$ of 7.5\% sodium carbonate solution was added and incubated again for 90 minutes at room temperature. The absorbance of all samples was measured at $760 \mathrm{~nm}$. The concentrations of the phenolic compounds are determined from the calibration curve. The results are expressed in milligram equivalent of gallic acid per gram of extract (mg EAG / g).

\section{Estimation of flavonoids content}

The method of Djeridane et al. 12 was used for this test. To $500 \mu \mathrm{l}$ of each extract (prepared with suitable dilutions in methanol) is added $500 \mu \mathrm{l}$ of $\mathrm{AlCl}_{3}$ (2\% in methanol). After 10 minutes of incubation, the absorbance reading is taken at $430 \mathrm{~nm}$. The flavonoids concentration is calculated using a calibration range established with quercetin $(2.5-40 \mu \mathrm{g} /$ $\mathrm{ml}$ ). The concentration is expressed in milligrams of quercitin equivalent per gram of extract ( $\mathrm{mg} E \mathrm{EQ} / \mathrm{g}$ ).

\section{Estimation of tanins content}

The modified method of Gharzouli et al. ${ }^{13}$ was applied for this study. Briefly, one volume of each plant extract was mixed with an equal volume of hemolyzed bovine blood (absorbance $=1.6$ ). After 20 minutes, the mixture was centrifuged at $4000 \mathrm{rpm}$ for 10 minutes and the absorbance of the supernatant was measured at $576 \mathrm{~nm}$. Results were expressed as mg tannic acid per gram of extract (mg EAT / g).

\section{Evaluation of antioxidant power}

\section{DPPH radical-scavenging activity}

The DPPH (2,2'-diphenyl-1-picryl hydrazyl) radical scavenging activity was determined according to the method described by Mayouf et al. ${ }^{14}$. A volume of $50 \mu \mathrm{l}$ of the extracts dilutions was added to $1250 \mu \mathrm{l}$ of a methanolic solution containing $0.004 \%$ DPPH. The mixture was kept at room temperature for 30 minutes before measuring its absorbance at $517 \mathrm{~nm}$. BHT (2, 6 di-tert-butyl-4-methyl phenol) was used as the reference standard. The radical scavenging activity was calculated as a percentage (I\%) as follows:

$$
\mathrm{I} \%=100 \text { (Abs control }- \text { Abs sample) } / \text { Abs control }
$$

Abs control is the absorbance of the DPPH solution, Abs sample is the absorbance in the presence of the extract.

The concentration of the extract providing $50 \%$ inhibition ( $\left.\mathrm{IC}_{50}\right)$ was calculated from the percentage of the inhibition curve relative to the concentration of the extract.

\section{Linoleic acid / $\beta$-carotene assay}

The antioxidant capacity was also determined by measuring the inhibition of the formation of conjugated diene hydroperoxides resulting from the oxidation of linoleic acid 15. An emulsion ( $2.5 \mathrm{ml}$ ) containing $\beta$-carotene, linoleic acid and Tween- 40 was added to $0.35 \mathrm{ml}$ of the sample, then incubated for $48 \mathrm{~h}$ at room temperature. The same procedure was repeated with the BHT as the positive control, and $\mathrm{H}_{2} \mathrm{O}$ as the negative control. The absorbance of the mixture was measured at $490 \mathrm{~nm}$ after $0,1,2,4,6,24$ and $48 \mathrm{~h}$. The antioxidant activity of the extracts was evaluated as a percentage of $\beta$-carotene bleaching:

$$
\mathrm{I} \%=\text { Abs sample } / \text { Abs sample }\left(\mathrm{t}_{0}\right) \times 100 .
$$

\section{Chelating power of iron}

The chelation of ferrous iron by the extracts is evaluated by the ferrozine method described by Belkheiri et al. ${ }^{16}$. Suitably diluted extracts $(250 \mu \mathrm{l})$ were mixed with $50 \mu \mathrm{l}$ of $0.6 \mathrm{mM}$ $\mathrm{FeCl}_{2}$ and $450 \mu \mathrm{l}$ of methanol. The reaction was initiated after 5 minutes by the addition of $50 \mu \mathrm{l}$ of ferrozine $(5 \mathrm{mM})$ and incubated for 10 minutes at room temperature. The absorbance of the $\mathrm{Fe} 2+-$ ferrozine complex was measured at $562 \mathrm{~nm}$. The chelating effect was calculated as a percentage and the $\mathrm{IC}_{50}$ was defined as the effective concentration of the extract which produces $50 \%$ of the maximum chelating effect. EDTA (Ethylene diamine tetraacetic) was used as a standard.

$$
\text { Chelating power }(\%)=\left[\left(A_{c}-A_{s}\right) / A_{c}\right] \times 100
$$

Ac: absorbance in the absence of chelator (control). $A_{s}$ : absorbance in presence of chelator (extracts or EDTA).

\section{Statistical analysis}

The values were generally expressed as a mean \pm SD. The results of the different tests are analyzed by the uni varied ANOVA test followed by the Tukey test for multiple comparisons and determination of significance rates. The comparison of the means and standard deviations is determined using the software "Graphpad Prism" version 5.0 .

\section{RESULTS}

\section{Yields of extraction}

The extraction yields showed that the Inf (7.25\%) gave the highest yield followed by Dec (4.9\%) then Mac (4.75\%). The differences observed between the yields of the aqueous extracts have no relation to the extraction solvent which is the same. This may be due to the extraction temperature.

\section{Determination of total polyphenol, flavonoids and tannins contents}

In order to characterize the extracts prepared, esrimation of polyphenols, flavonoids and tannins was carried out. The results are shown in table 1. 
Table 1 : The contents of total polyphenols, flavonoids and tannins in extracts from the aerial part of AT.

\begin{tabular}{|c|c|c|c|}
\hline Extracts & $\begin{array}{l}\text { Polyphenols } \\
\text { (mg EGA/g E }{ }^{\circ}\end{array}$ & $\begin{array}{c}\text { Flavonoids } \\
(\mathrm{mg} \mathrm{EQ} / \mathrm{g} \mathrm{E})^{\circ \circ}\end{array}$ & $\begin{array}{c}\text { Tannins } \\
(\mathrm{mg} \text { ETA } / \mathrm{g} \mathrm{E})^{\circ \circ}\end{array}$ \\
\hline Decoction & $173.28 \pm 43.1$ & $14.62 \pm 1.71$ & $40.27 \pm 15.00$ \\
\hline Maceration & $144.50 \pm 20.66$ & $1.98 \pm 0.46$ & $17.69 \pm 9.63$ \\
\hline Infusion & $189.66 \pm 30.77$ & $26.80 \pm 8.37$ & $40.25 \pm 18.27$ \\
\hline \multicolumn{4}{|c|}{${ }^{\circ}$ : equivalent of milligrams of gallic acid per gram of extract weight (mg EGA/g E). } \\
\hline \multicolumn{4}{|c|}{${ }^{\circ \circ}$ : equivalent of milligrams of tannic acid per gram of extract weight (mg ETA/ g E). } \\
\hline
\end{tabular}

Results of the estimation of polyphenols show that Inf is the richest in phenolic compounds $(189.66 \pm 30.77 \mathrm{mg}$ EGA / g of extract) followed by Dec (173.28 $\pm 43.1 \mathrm{mg}$ EGA / $\mathrm{g}$ of extract), then Mac $(144.50 \pm 20.66 \mathrm{mg}$ EGA / g of extract). The quantitative estimation of the flavonoids shows that Inf (26.80 $\pm 8.37 \mathrm{mg} \mathrm{EQ} \mathrm{/} \mathrm{g}$ of extract) is the richest in flavonoids, followed by Dec (14.62 $\pm 1.71 \mathrm{mg}$ EQ / $\mathrm{g}$ of extract) then the Mac $(1.98 \pm 0.46 \mathrm{mg} \mathrm{EQ} \mathrm{/} \mathrm{g} \mathrm{of} \mathrm{extract})$ respectively.

The results of the assay also show that the content of polyphenols is significantly higher than that of flavonoids, this suggests that the polyphenols present are not all flavonoids, there may be presence of other polyphenols such as tannins which have been highlighted in the present study.

Estimation of total tannins reveal that Dec $(40.27 \pm 15.00 \mathrm{mg}$ ETA / g of extract) and Inf (40.25 $\pm 18.27 \mathrm{mg}$ ETA / g of

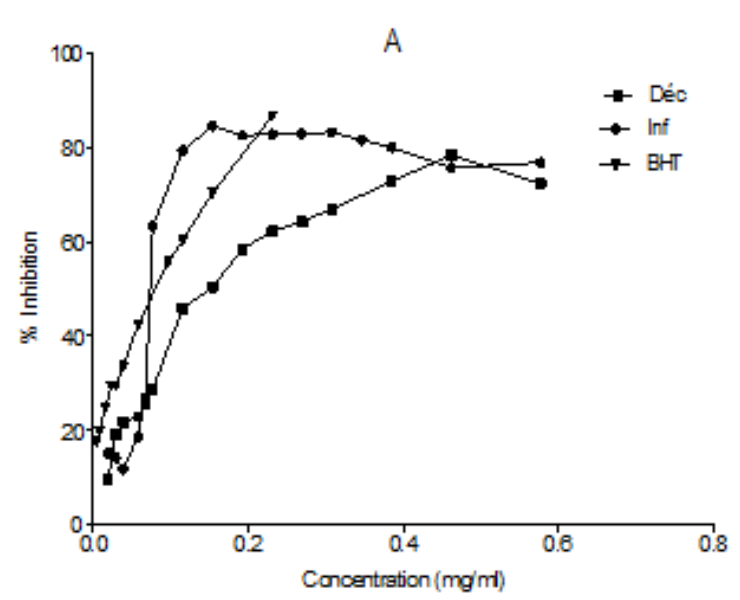

extract) are the richest in tannins with very similar values, followed by Mac (17.68 $\pm 9.63 \mathrm{mg}$ ETA / $\mathrm{g}$ of extract).

\section{Antioxidant activity of Alkanna tinctoria extracts DPPH scavenging activity}

The anti-radical activity of the various extracts was evaluated by their inhibitory activity on a methanolic solution of DPPH, measured at $517 \mathrm{~nm}$. The standard used was BHT. The anti-free radical activity of the various AT extracts, as well as the BHT, has been illustrated in figure 1 . It is noted that the AT extracts have a dose-dependent antifree radical activity, except the extract of the maceration, which has apparently a pro-oxidant effect. The $\mathrm{IC}_{50}$ of the different extracts were determined. A lower value of the $\mathrm{IC}_{50}$ (the concentration of the substrate that causes a $50 \%$ inhibition of DPPH activity) indicates higher antioxidant activity.

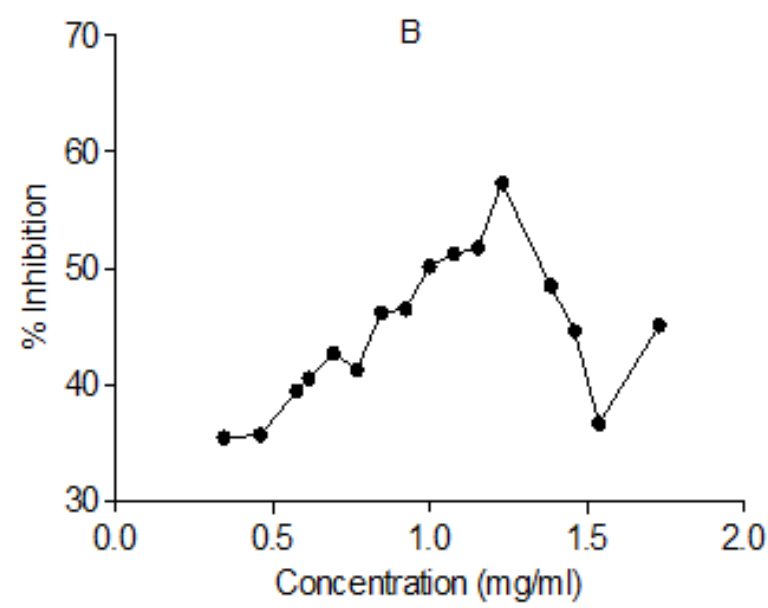

Figure 1: Scavenger effect of decoction (Dec), infusion (Inf) and BHT (A) and maceration (B) of Alkanna tinctoria, (The values are the average of three measurements).

The extract of the Inf presents an $\mathrm{IC}_{50}$ of $0.09 \pm 0.001 \mathrm{mg} /$ $\mathrm{ml}$ followed by the extract of the Dec with an IC 50 of $0.17 \pm$ $0.031 \mathrm{mg} / \mathrm{ml}$ and finally the Mac with an $\mathrm{IC}_{50}$ of the order of $1.006 \pm 0.111 \mathrm{mg} / \mathrm{ml}$. The difference is not significant between the BHT ( $\mathrm{IC}_{50}$ of $0.087 \pm 0.001 \mathrm{mg} / \mathrm{ml}$ ) and the two extracts: Inf and Dec. On the other hand, the effectiveness of the macerate is very low compared to BHT $(* * *, p \leq 0.001)$ (Figure 2). 


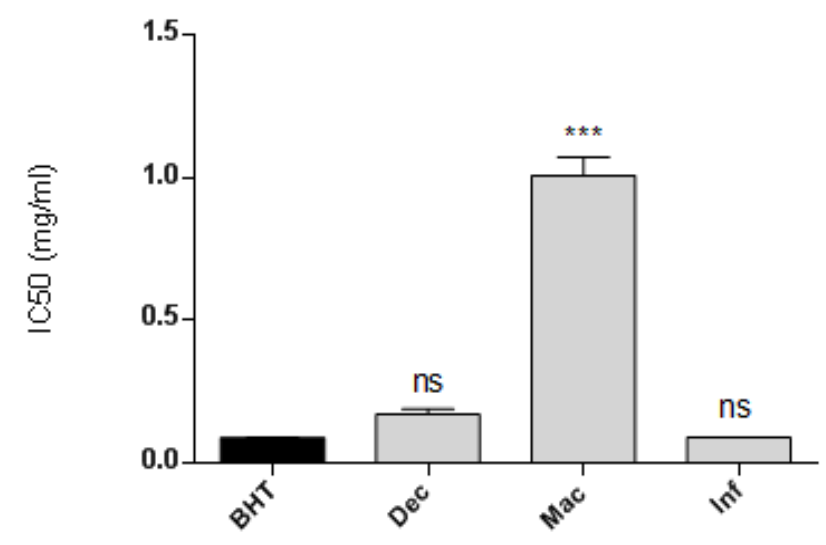

Figure 2: $\mathrm{IC}_{50}$ of the aqueous extracts of the aerial part of Alkanna tinctoria and of BHT on the DPPH radical, (The values of the $\mathrm{IC}_{50}$ are the average of three measurements \pm SD).

\section{Linoleic acid / $\beta$-carotene assay}

The bleaching of $\beta$-carotene was greatly slowed down in the presence of the two extracts Inf and Dec with antioxidant activities $100 \pm 9.23 \%, 99.82 \pm 9.62 \%$ respectively. While the Mac shows an activity of $55.22 \pm 5.54 \%$. (Figure 3 ).

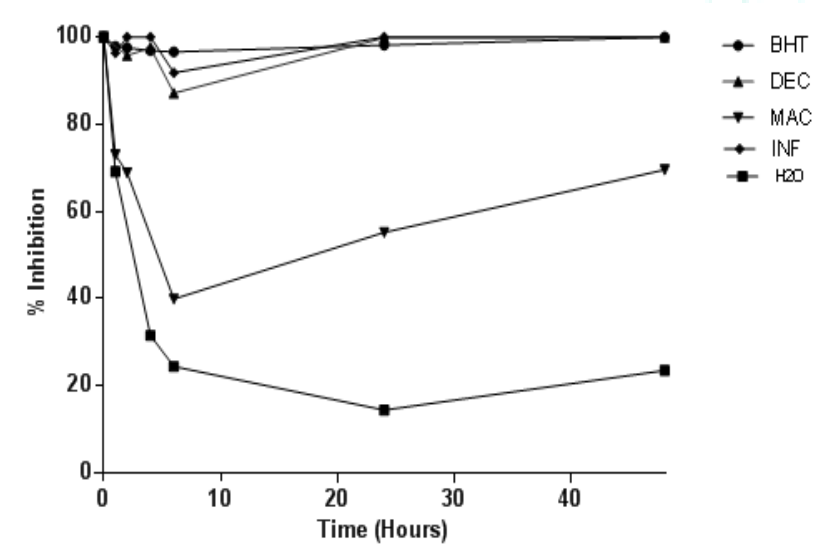

Figure 3: Bleaching kinetics of $\beta$-carotene at $490 \mathrm{~nm}$ in the presence of extracts of Alkanna tinctoria and BHT (the values are the average of three measurements).

The difference is not significant between BHT and the two extracts Dec and Inf ( $\mathrm{p} \leq 0.001$ ) (Figure 4). Moreover, the difference is significant between the BHT $(98.15 \% \pm 0.75)$ and the $\operatorname{Mac}\left({ }^{* *}, \mathrm{p} \leq 0.001\right)$.

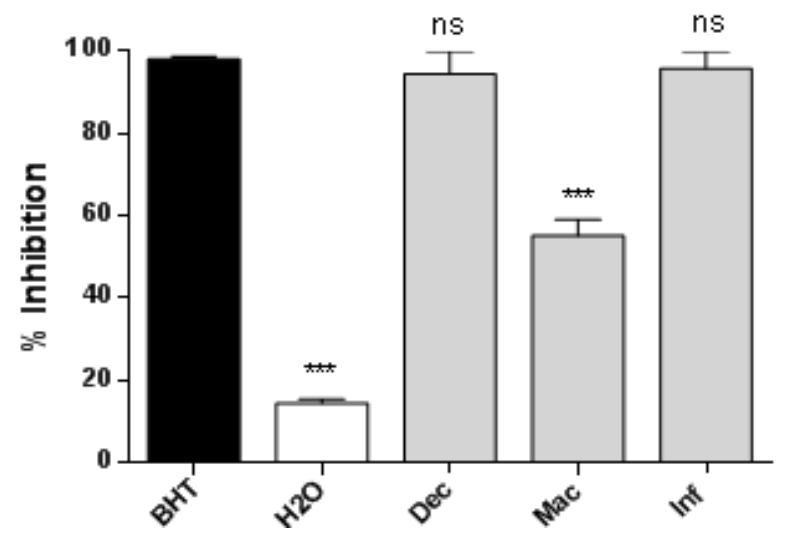

Figure 4: Antioxidant activity of extracts of the aerial part of Alkanna tinctoria and of BHT in the $\beta$-carotene / linoleic acid system, (the values are the mean of three measurements \pm SD) $(p \leq 0.001)$.

\section{Chelating power of iron}

The results obtained show that the aqueous extracts of the aerial part of AT have concentration-dependent chelating activity (Figure 5).

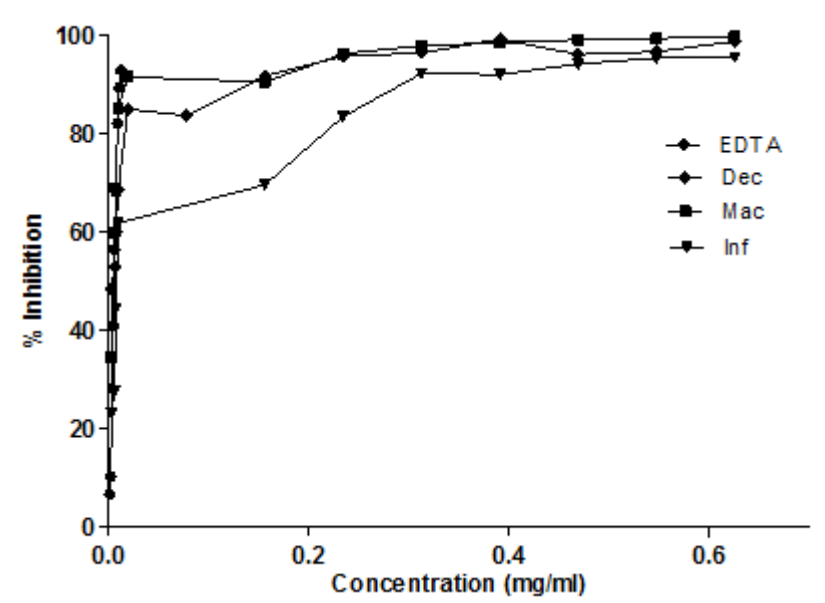

Figure 5 : Metal chelating activity at $562 \mathrm{~nm}$ in the presence of extracts of Alkanna tinctoria and EDTA, (Values are the average of three measurements).

The Dec extract has an IC50 of $0.003 \pm 0.0002 \mathrm{mg} / \mathrm{ml}$ followed by the Mac with an IC50 of $0.005 \pm 0.00008 \mathrm{mg} /$ $\mathrm{ml}$ and finally the Inf with an IC50 of around $0.009 \pm 0.0008$ $\mathrm{mg} / \mathrm{ml}$. So Dec has the strongest chelating activity among the three extracts. The difference is not significant between EDTA (IC50 of $0.006 \pm 0.00007 \mathrm{mg} / \mathrm{ml}$ ) and MAC but significant between EDTA and the two aqueous extracts: Inf and $\operatorname{Dec}\left({ }^{* *}, \mathrm{p} \leq 0.001\right)$ (Figure 6).

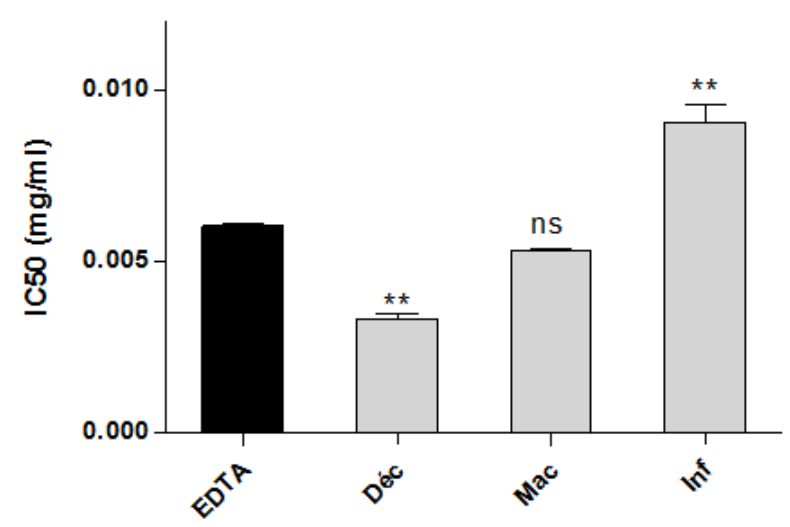

Figure $6: \mathrm{IC}_{50}$ of aqueous extracts from the aerial part of Alkanna tinctoria and EDTA, (values are the mean of three measurements \pm SD) $(p \leq 0.001)$.

\section{DISCUSSION}

The estimation of the contents of phenolic compounds, flavonoids and tannins makes it possible to correlate the results obtained with the antioxidant activity of the extracts tested.

The Folin-Ciocalteu test gives a crude estimate of the total phenolic compounds present in an extract. It is not specific to polyphenols, but many interfering compounds can react with the reagent, giving apparent high phenolic concentrations. In addition, various phenolic compounds react differently in this test, depending on the number of phenolic groups they have ${ }^{17}$. 
However, at high temperatures, water also extracts unwanted substances such as proteins, lipids and nonphenolic dyes that interfere with the determination of tannins. We can then conclude that the extraction of condensed tannins depends on their chemical nature, the solvent used and the operating conditions. However, the contents of condensed tannins can also be variable due to several factors such as: the sensitivity of the tannins to several degradation pathways (oxidation, light, etc.), cultural and climatic conditions 18 .

According to Tiwari et al. ${ }^{19}$, the amount and composition of secondary metabolites of an extract depend on: type of extraction, extraction time, temperature, nature of the solvent, concentration of solvent and polarity.

Antioxidants can exert their protecting effects by various mechanisms, radical scavenging or preventing the generation of ROS; they act by inhibiting the initiation and propagation steps leading to the termination of the reaction and delay the oxidation process. They also act by binding of transition metal ion catalysts, and subsequently, they retard the progress of many chronic diseases 20.

In this context, Three methods are used to assess antioxidant activity, the DPPH scavenging, the $\beta$-carotene bleaching and the iron chelation tests.

The DPPH radical scavenging assay is a simple, fast and sensitive method for the antioxidant screening of plant extracts 21. The anti-radical activity is measured by the discoloration of DPPH, which is a relatively stable free radical, from purple to a yellow color. The discoloration explains the power of the plant extract to scavenge this radical.

In this test, a correlation between the contents of phenolic compounds and the DPPH scavenging activity is observed in the case of the three extracts. In fact, Falleh et al. ${ }^{22}$ have shown that there is a very significant correlation between the content of polyphenols (total polyphenols, flavonoids and condensed tannins) and the scavenging effect of DPPH radicals. On the other hand, Albano and Miguel 23 reported that this correlation is not always present.

Oxidation of linoleic acid generates peroxide radicals, these free radicals will subsequently oxidize $\beta$-carotene causing the disappearance of its red color, which is followed by spectrophotometry at $490 \mathrm{~nm}$. However, the presence of an antioxidant could neutralize free radicals derived from linoleic acid and therefore prevent the oxidation and bleaching of $\beta$-carotene. In this test, the antioxidant capacity is determined by measuring the inhibition of the oxidative degradation of $\beta$-carotene (discoloration) by the oxidation products of linoleic acid 24 .

This method is widely used because $\beta$-carotene shows strong biological activity and is an important physiological compound ${ }^{18}$. Therefore, it is used in the evaluation of the antioxidant activity of AT extracts. An extract that inhibits $\beta$ carotene bleaching can be described as a free radical scavenger and primary antioxidant 25 .
AT extracts have the ability to react with free radicals to convert them into non-reactive species and interrupt the chain of radical reactions. Flavonoids and polyphenols in general have the ability to scavenge free radicals and therefore delay the auto-oxidation of lipids 26 . They inhibit lipid peroxidation at an early stage by scavenging peroxide radicals, as they can interrupt the chain of radical reactions by giving off hydrogen 27 .

This ability to modify lipid peroxidation induced by free radicals is related not only to the structural characteristics of antioxidant agents but also to their ability to penetrate and interact with lipid bilayers. The structure and lipophilicity of polyphenols have been shown to be important factors underlying the antioxidant property, possibly affecting the depth of incorporation of these compounds into the lipid phase of the membrane 28 .

Transition metals, such as ferrous ions, can stimulate lipid peroxidation by generating hydroxyl radicals by the Fenton reaction and accelerate lipid peroxidation by breaking down lipid hydroperoxides into peroxyl and alkoxyl radicals, thus driving the chain reaction of the lipid peroxidation. The $\mathrm{Fe}^{2+}$ ion is the strongest pro-oxidant among the various species of metal ions. Ferrozine can quantitatively form complexes with $\mathrm{Fe}^{2+}$. In the presence of chelating agents, the formation of the complex is disturbed, which leads to a decrease in the red color of the complex. Measuring the reduction in color therefore makes it possible to estimate the chelating activity of the metals of the coexisting chelator. Lower absorbance indicates higher metal chelating activity 29.

Dec and Mac AT extracts exhibit considerable chelating activity. However, the latter two are better than the Inf. This could be attributed to the solubility of chelating agents in water. Sahreen et al. 30 have shown that plant extracts chelating effects are directly proportional to the polarity of their solvents. The aqueous constituents are more able to inhibit the formation of the $\mathrm{Fe}^{2+}$ - ferrozine complex, capturing the ferrous ions before the ferrozine. Chelating agents have been reported to be effective as secondary antioxidants because they reduce the redox potential by stabilizing the oxidized form of metal ions 31 .

\section{CONCLUSION}

According to the results of this study, aqueous extracts of Alkanna tinctoria possess significant antioxidant activity in vitro. They show a very significant inhibition vis-à-vis the DPPH radical, an excellent inhibitory effect on lipid peroxidation and / or scavenging of radicals resulting from the oxidation of linoleic acid and a strong chelating activity vis-à-vis ferrous iron. These activities may be due to phytochemical constituents present in these extracts.

\section{ACKNOWLEDGEMENTS}

This work was supported by the Algerian Ministry of Higher Education and Scientific Research (MHESR). 


\section{REFERENCES}

[1]: Zerargui F, Boumerfeg S, Charef N, Baghiani A, Djarmouni M, Khennouf S, Arrar L, Musa H. Abu Zarga, Mohammad SM. Antioxidant Potentials and Xanthine Oxidase Inhibitory Effect of Two Furanocoumarins Isolated from Tamus communis L. Med. Chem. 2015; 11:506-513.

[2]: Ou J, Wang M, Zheng J, and Ou, S. Positive and negative effects of polyphenol incorporation in baked foods. Food chem. 2019; 284:90-99.

[3]: Elsharkawy E, Elshathely M, Abdeljaleel G, Ibrahim Aljohar H. Anti-inflammatory effects of medicinal plants mixture used by Bedouin people in Saudi Arabia. Herba Pol. 2013; 59 (3):76-87.

[4]: Salimikia I, Yazdinezhad AR, Golfakhrabadi F, Esfahani HRM. In vitro antioxidant and free radical scavenging activity of four Alkanna species growing in Iran. Pharmacog. Res. 2015; 7 (1):100-104

[5]: Kourounakis AP, Assimopoulou AN, Papageorgiou VP Gavalasa A , Kourounakis PN. Alkannin and Shikonin: Effect on Free Radical Processes and on Inflammation - A Preliminary Pharmacochemical Investigation. Arch. Pharm. Pharm. Med. Chem. 2002; 6:262-266.

[6]: Khan UA, H Rahman H, Qasim M, Hussain A, Azizullah Azizllah3, Murad W, Khan Z, Anees M and Adnan M. Alkanna tinctoria leaves extracts: a prospective remedy against multidrug resistant human pathogenic bacteria. BMC Complem Altern. Med. 2015; 15(127):1-6.

[7]: Yousefi R, Ghaffarifar F, Dalimiasl A.The Effect of Alkanna tincturia and Peganum harmala extracts on Leishmania major (MRHO/IR/75/ER) in vitro. Iran. J Parasitol. 2009; 4 (1):40-47.

[8]: Ferreira A, Proença C, Serralheiro MLM andAraùjo MEM.The in vitro screening for acetylcholinesterase inhibition antioxidant activity of medicinal plants from Portugal. J. Ethnopharmacol. 2006; 108:31-37,.

[9]: Khadhri A, El mokhi R et Smiti S. Composé phenoliques et activité antioxydantes de deux extraits de chardon aglu: Atractylis gummifera. Revue Soc. Sci. Nat. de Tunisie. 2013; 39:44-52.

[10]: Valentao AP, Fernandes E, Carvalho F, Andrade PB, Seabra RM, and Bastos ML. Studies on the Antioxidant Activity of Lippia citriodora Infusion: Scavenging Effect on Superoxide Radical, Hydroxyl Radical and Hypochlorous. Biol. Pharm. Bull. 2002; 25:1324-1327.

[11]: Bentaher A, Khennouf S, Bouaziz A, Baghiani A, Dahamna S, Amira S, Arrar L. Polyphenols Content and Antioxidant Activities of Selected Algerian Plants Used for Gastroduodenal Ulcers. Der Pharma Chemica 2016 ; 8:88-99.

[12]: Djeridane A, Yousfi M, Nadjemi B, Boutassouna D, Stocker AP, Vidal N. Antioxidant activity of some algerian medicinal plants extracts containing phenolic compounds. Food Chem. 2006; 97:654-660.

[13]: Gharzouli K, Khennouf S, Amira S and Gharzouli A.Effects of Aqueous Extracts from Quercus ilex L. Root Bark, PunicagranatumL. Fruit Peel and Artemisia herba-alba Asso Leaves on Ethanol-induced Gastric Damage in Rats. Phytother. Res 1999; 13:42-45.

[14]: Mayouf N, Charef N, Saoudi S, Baghiani A, Khennouf S, Arrar L. Antioxidant and anti-inflammatory effect of Asphodelus microcarpus methanolic extracts. J. Ethnopharmacol. 2019; 239:1-9.

[15]: Amamra S, Charef N, Arrar L, Belhaddad O, Khennouf S, ZAIM K, Baghiani A. Phenolic content, antioxidant and antibacterial effects of fruit extracts of Algerian Ash, Fraxinus excelsior. Indian J. Pharm. Sci. 2018;80(6):1021-1028.

[16]: Belkhiri F, Baghiani A, Zerroug MM and Arrar L. Investigation of antihemolytic, xanthine oxydase inhibition,antioxydant and antimicrobial properties of SalviaVerbenacaL. Aerial part extracts. Afr. J. Tradit. Complement. Altern. Med. 2017; 14 (2):273-281.

[17]: Tawaha K, Alali FQ, Gharaibeh M, Mohammad M, ElElimat T. Antioxidant activity and total phenolic content of selected Jordanian plant species. Food Chem. 2007; 104:1372-1378.

[18]: Ghedadba N, Bousselsela H., Hambaba L, Benbia S et Mouloud Y. Évaluation de l'activité antioxydante et antimicrobienne des feuilles et des sommités fleuries de Marrubium vulgare L. Phytothérapie. 2014; 12:15-24.

[19]: Tiwari P, Kumar B, Kaur M, Kaur G, Kaur H. Phytochemical screening and Extraction: A Review. Intern. Pharmac. Sc. 2011; 1:98-106.

[20]: Laouicha S, Senator A, Kherbache A, Bouriche H. Total phenolic contents and antioxidant properties of Algerian Arbutus unedo L. Extracts. J. Drug Deliv. Ther. 2020; 10(3s):159-168.

[21]: Nur Alam Md, JahanBristi N, Rafiquzzaman Md. Review on in vivo and in vitro methods evaluation of antioxidant activity. Saudi Pharmaceut. J. 2013; 21:143-152.

[22]: Falleh H, Ksouri R, Chaieb K, Karray-BouraouiN,Trabelsi $\mathrm{N}$, Boulaaba $\mathrm{M}$ and Abdelly C. Phenolic composition of Cynaracardunculus L. organs, and their biological activities.Comptes Rendus Biologies. 2008 ; 331:372-379.

[23]: Albano SM, Miguel MG. Biological activities of extracts of plants grown in Portugal. Indus. Crops Prod. 2010; 1-6.

[24]: Laguerre $M$, Lecomte J, villeneuve P. Evaluation of the ability of antioxidants to counteract lipid oxidation: existing methods, new trends and challengres. Progression in lipid research. 2007; 46(5):244-82.

[25]: Ameni DJ, Baghiani A, Boumerfeg S, Dahamna S, Khennouf S, Musa $\mathrm{H}$. Abu zarga and Arrar L. Phytochemical profiles, antioxydants capacity and protective effect against aaph-induced mouse erythrocyte damage by daphne gnidium L. shoot extracts. Int. J Pharm. Pharm. Sci. 2015; 7:148-156.

[26]: Gao X, Bjork L, Trajkovski V, Uggla M. Evaluation of antioxidant activities of rosehip ethanol extracts in different test systems. J Sci. Food Agric. 2000; 80:20212027.

[27]: Sandhar HK, Kumar B , Prasher S, Tiwari P, Salhan M, Sharma P.A Review of phytochemistry and pharmacology of flavonoids. Internat. Pharmac. Sci. 2011; 1:25-41.

[28]: Djeridane A, Yousfi M, Brunel JM, StockerP.Isolation and characterization of a new steroid derivative as a powerful antioxidant from Cleome arabica in screening the in vitro antioxidant capacity of 18 Algerian medicinal plants. Food Chem. Tox. 2010; 48:2599-2606.

[29]: Gulcin I. Comparisonof in vitro antioxidant and antiradical activities of L-tyrosine and L-Dopa. Amino Acids. 2007; 32:431-438.

[30]: Sahreen S, Khan MR, Khan RA. Evaluation of antioxidant activities of various solvent extracts of Carissa opaca fruits. Food Chem. 2010; 122: 1205-1211.

[31]: Gülçin I, Elmastat M, Aboul-Enein HY. Determination of Antioxidant and Radical Scavenging Activity of Basil (Ocimum basilicum L. Family Lamiaceae) Assayed by Different Methodologies. Phytother.Res. 2007; 21:354361. 